\title{
Utilization of Recycled Coarse Aggregate in Concrete
}

\section{Mixes}

\author{
Akmal Abdelfatah, Sami Tabsh and Sherif Yehia \\ Civil Engineering Department, American University of Sharjah, UAE
}

\begin{abstract}
In this paper, the effect of the source of recycled coarse aggregate on the properties of concrete is investigated. The tests were conducted on concrete made from three sources of recycled aggregates: (1) old concrete with unknown strength, (2) old concrete with a known compressive strength of $21 \mathrm{MPa}$, and (3) old concrete with a known strength of $42 \mathrm{MPa}$. The three sources of recycled aggregates were used to produce new concrete with a target compressive strength of $21 \mathrm{MPa}$. The first and third sources of recycled aggregates were used in producing concrete with target strength of $42 \mathrm{MPa}$. A control mix was designed with aggregates from natural sources. The research included two methods of making recycled concrete. One concrete mix was produced using the recycled aggregate and adding more water than the control mix, to reach the target slump, while the second concrete mix was produced using the same amount of water as the control mix but with additional superplasticizer to maintain the target slump. The results obtained in this research showed that the concrete compressive strength depends on the source of recycled aggregates; the stronger the source of recycled aggregate, the higher the compressive strength of the produced concrete. Furthermore, the compressive strength of the first concrete mix was about 10\%-20\% lower than the compressive strength of the control mix. However, when superplasticizers were used, the compressive strength was around the same value as the control mix.
\end{abstract}

Key words: Compressive strength, concrete, environment, recycled concrete.

\section{Introduction}

Aggregates represent about 60\%-70\% per volume of any concrete mixture. The growth of the new construction projects and the increasing demand for natural aggregates led to the expected shortage of the natural resources. In addition, several environmental and economical factors were the reason for the search of other alternatives. Therefore, the feasibility of using recycled aggregate as a partial or full replacement of natural aggregate was the focus of the research over the past few decades.

Several environmental, economical, and engineering benefits could be achieved from recycling the construction industry waste. Recycled aggregates provide an alternative of the natural aggregate if quality is assured. However, the quality of the aggregate can

Corresponding author: Akmal Abdelfatah, associate professor, research fields: transportation engineering and construction materials.E-mail: akmal@aus.edu. vary due to many factors that affect the consistency, properties, and quality. Some of these factors are: source of the recycled aggregate, stresses, exposure and environmental conditions, method of crushing, and cleanliness of the new recycled product. In addition, several other barriers limit the use of the recycled aggregate in many applications. These barriers include higher initial cost, variation in quality, lack of codes, specifications, standards and guidelines. Many research efforts were devoted to providing solutions and overcoming many of these barriers.

\section{Background}

Recycled aggregates are produced from reprocessing old or used concrete, with the largest source being construction, renovation, and demolition waste. During this process of crushing, desired aggregate size can be obtained. The concerns about the physical and mechanical properties have limited the use of the recycled aggregates to specific applications. 


\subsection{Current Market}

An estimated 95 million metric tons of concrete are recycled each year in the United States [1]. Approximately $68 \%$ of the recycled concrete is used as a road base [2, 3], while the remainder is used for new concrete mixes (6\%), asphalt hot mixes (9\%), high volume riprap (3\%), low value products like general fill (7\%), and others (7\%). However, many State Departments of Transportation (DOTs) either specify a limited spectrum of applications for Recycled Aggregates (RA) in concrete or do not allow its use in concrete at all. These limitations are influenced by the perceived variation in quality and the lack of available acceptance criteria of the recycled aggregate.

\subsection{Engineering Properties of RAC}

Many research efforts have demonstrated an inverse relationship between the amount of RA used and the quality of the new concrete mix [4-10]. Durability, porosity, and mechanical properties of concrete made with recycled aggregate were affected by the percentage of recycled aggregate used. Results [11-16] indicated that $50 \%$ recycled aggregates content was the optimum amount that can be used in a concrete mix for structural applications to meet specific mix requirements. In addition, physical properties of recycled aggregates must be evaluated to adjust the mixture proportioning to achieve the required behavior. Table 1 summarizes some of recycled aggregate properties which were reported in the literature.

The experimental results presented in this paper discuss the effect of absorption capacity and effect of using admixtures on strength of concrete produced with different recycled aggregates.

\section{Research Plan}

In this study, three different kinds of coarse aggregates are considered: (1) recycled from hardened concrete with compressive strength $\left(f_{c}^{\prime}\right)=21 \mathrm{MPa}$, and (2) recycled from hardened concrete with $f_{c}^{\prime}=42 \mathrm{MPa}$, and (3) recycled from unknown source. Furthermore, concrete made with natural coarse aggregate is also considered for bench-marking purposes.

The experimental program consisted of testing hardened $150 \mathrm{~mm}$ by 300 mmconcretecylinders in the laboratory. The strength properties of concrete were obtained at 7, 14 and 28 days. In all cases, each data point represents the average value of two samples.

Table 1 Summary of some engineering properties of recycled aggregate.

\begin{tabular}{|l|l|}
\hline Physical/Mechanical property & \\
\hline Gradation & Usually does not meet the graduation requirements because of the demolishing process [4, 5]. \\
\hline Particle shape & Recycled aggregate is found to be angular in shape [6] which leads to workability reduction. \\
\hline Specific gravity & $\begin{array}{l}\text { Typical values of specific gravity of recycled aggregates were found to be in the ranges of 2.2 and } \\
2.5 \text { in the saturated surface dry condition [6, 7]. This range is about 5\% to 10\% [6] lower than that } \\
\text { of natural aggregates. }\end{array}$ \\
\hline Water absorption & Depending upon the source of aggregate, the water absorption is in the range of 2\% to 6\% [7]. \\
\hline Permeability & It is more permeable than natural aggregate [8]. \\
\hline Durability/Abrasion loss & The abrasion loss for recycled aggregate concrete is found to be in the range of 20\% to 45\% [7]. \\
\hline Alkali-Silica Reactivity (ASR) & $\begin{array}{l}\text { Recycled aggregate has higher tendency towards alkali-silica reactions when exposed to alkaline } \\
\text { pore water as compared to virgin aggregates [9]. }\end{array}$ \\
\hline Compressive strength & has 25\% [8, 15] less compressive strength than that of natural aggregate. \\
\hline Flexural strength & $\begin{array}{l}\text { about 10\% lower flexural strength at equal water cement ratio and slump than natural aggregate } \\
\text { concrete [6]. }\end{array}$ \\
\hline $\begin{array}{l}\text { Creep, Shrinkage, and Resistance } \\
\text { to Freeze-thaw }\end{array}$ & $\begin{array}{l}\text { Concrete with recycled aggregates has high tendency towards creep and shrinkage [10]. It was also } \\
\text { found that results in resistance to freeze-thaw were satisfactory, provided a suitable air void system } \\
\text { is present in the mortar stage of concrete [8]. }\end{array}$ \\
\hline
\end{tabular}




\section{Results}

\subsection{Phase I: Additional Water; without Admixtures}

In this phase, two concrete mixes were considered. One mix had a 28-day target strength equal to $f_{c}^{\prime}=21$ $\mathrm{MPa}$ and another mix had a target strength of $f_{c}^{\prime}=42$ MPa. Both concrete mixes were proportioned for a 100 mm slump. Due to its high porosity and absorption, concrete made with recycled coarse aggregate required about $10 \%$ more water than conventional concrete.

Figs. 1 and 2 show the compressive test results for the natural and recycled concrete with target strengths of 21 and $42 \mathrm{MPa}$, respectively. Test results for the recycled concrete included concrete made with recycled aggregates from known $\left(f_{c}^{\prime}=21\right.$ or $\left.42 \mathrm{MPa}\right)$ and unknown sources. The results are plotted for the strength at the age of 7, 14 and 28 days. They indicate that the strength of recycled concrete depends on the target strength. For a low target strength (21 MPa), recycled concrete is only $10 \%$ weaker than its natural counterpart at the age of 28 days. However, for a high target strength (42 $\mathrm{MPa}$ ), the strength properties of the coarse aggregates greatly affects the strength of the concrete and can reduce the strength by as much as $30 \%$. The reduction in strength of concrete made with recycled aggregates is mainly due to the lower strength of the recycled coarse aggregates and the additional water needed to maintain a $100 \mathrm{~mm}$ slump, without the use of chemical admixtures.

\subsection{Phase 2: Using Admixtures}

In this phase, two concrete mixes were considered. One mix had a 28-day target strength equal to $f_{c}^{\prime}=21$ $\mathrm{MPa}$ and another mix had a target strength of $f_{c}^{\prime}=42$ $\mathrm{MPa}$. Both concrete mixes were proportioned for a 100 mm slump. In order to achieve the target slump and improve the strength of the concrete, superplasticizers are added. An amount of 82-85 $\mathrm{ml}$ has been added to different mixes to achieve the target slump.

Figs. 3 and 4 show the compressive test results for the natural and recycled concrete with target strengths of 21 and $42 \mathrm{MPa}$, respectively. The results shown in the two figures show a significant improvement in the 28-day compressive strength for the concrete made from recycled aggregates. For $21 \mathrm{MPa}$ target strength, the recycled concrete is only about $5 \%$ weaker than the concrete mix made with natural aggregate. For the stronger concrete with a target strength of $42 \mathrm{MPa}$, the concrete made with recycled aggregate of a known source (42 $\mathrm{MPa}$ ) showed an improvement in the 28-days strength of about $12 \%$ over the natural aggregate mix.

It should be noted that the results obtained from the unknown source recycled aggregate were much higher than the natural aggregate. This could be attributed to the quality of the unknown source of recycled aggregate that affected the total strength of the concrete mix.

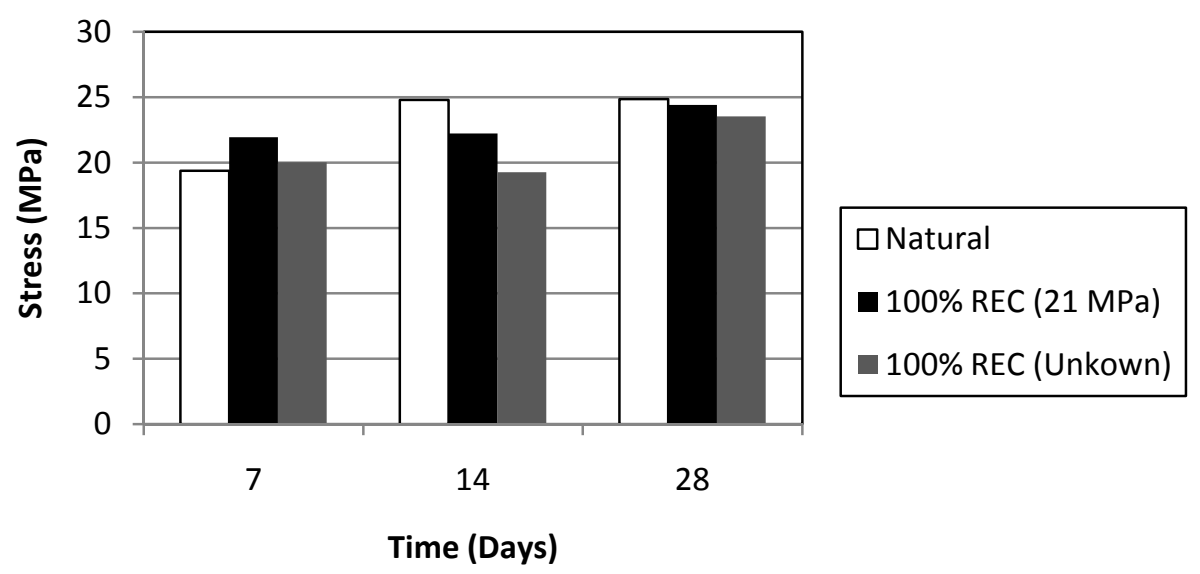

Fig. 1 Phase I-concrete compressive strength versus time for $f_{c}^{\prime}=21 \mathrm{MPa}$. 


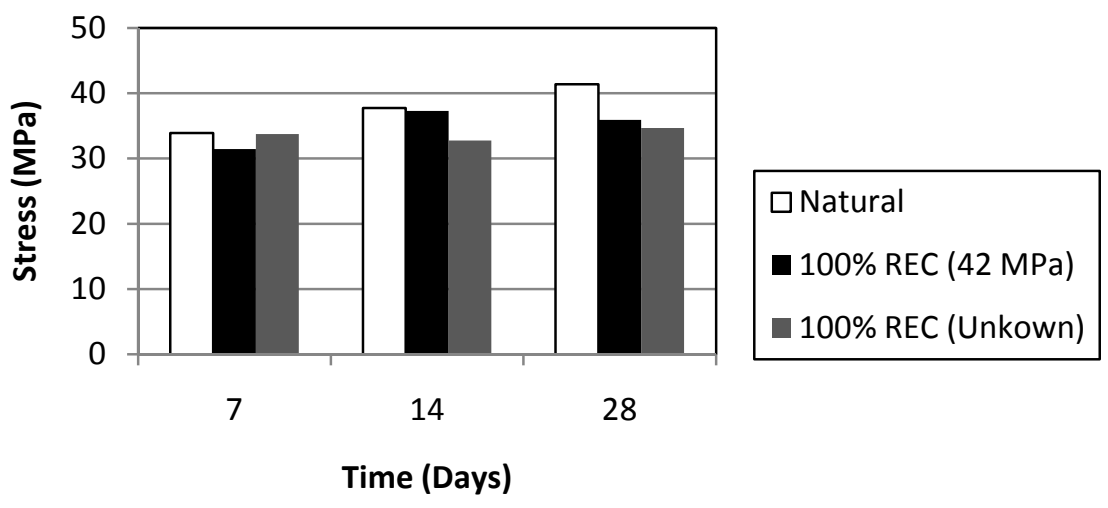

Fig. 2 Phase I-concrete compressive strength versus time for $f_{c}^{\prime}=42 \mathrm{MPa}$.

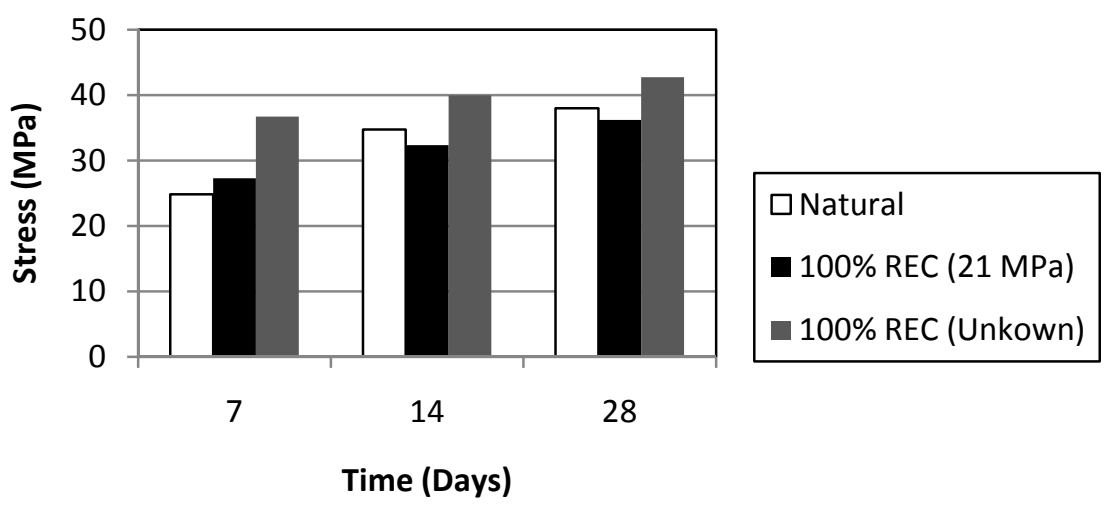

Fig. 3 Phase II-concrete compressive strength versus time for $f_{c}^{\prime}=21 \mathrm{MPa}$.

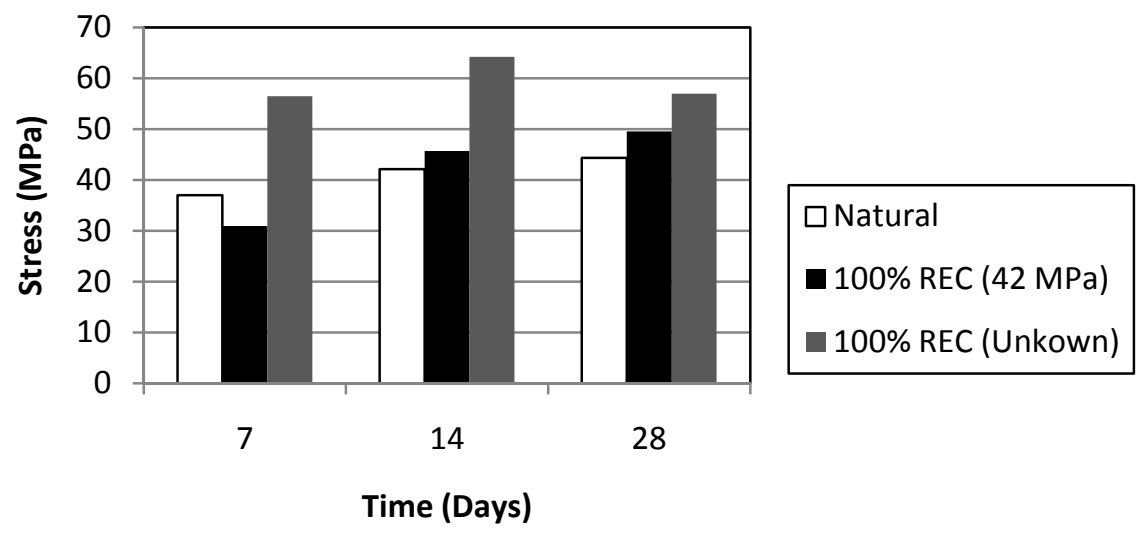

Fig. 4 Phase II-concrete compressive strength versus time for $f_{c}^{\prime}=42 \mathrm{MPa}$.

\section{Conclusion}

Recycled concrete can be used as coarse aggregate to produce new concrete mixes with reasonable strength.

Adding more water than the amount used for conventional concrete to achieve a given slump can reduce the strength of concrete made with recycled coarse aggregate by $10 \%-30 \%$.

Adding superplasticizers while maintaining the same amount of water used for conventional concrete can improve the strength of concrete made with recycled coarse aggregate by up to $12 \%$. 


\section{Acknowledgements}

This research was partially supported by an AUS research grant. The authors would like to acknowledge the support of AUS undergraduate students Salam Abdalla, Fadi Abuhousa, Hamed Farbod, and Hamid Alipour, who participated in this project.

\section{References}

[1] W. Turley, Headline News: C\&D materials are recycled at an impressive rate: Now if only America knew about it, C\&D Recycler 4 (6) (2002) 20-24.

[2] United States Geological Survey, Fact Sheet FS-181-99, Feb., 2000.

[3] Available online at: http://pubs.er.usgs.gov/usgspubs /fs/fs18199, accessed in January 2010.

[4] D. R. Wilburn and T. G. Goonan, Aggregates from natural and recycled sources, U.S. Geological Survey Circular 1176, 1998, available online at: http://greenwood.cr.usgs.gov/pub/circulars/c1176.

[5] M. Mashand and K. Sobhan, Fatigue behavior of a pavement foundation with recycled aggregate and waste HDPE strips, Journal of Geotechnical and Geo Environmental Engineering 129 (7) (2003) 630-638.

[6] M. Mashnad, T. Ahmad and K. Sobhan, Use of discrete fibers for tensile reinforcement of an alternative pavement foundation with recycled aggregate, Cement, Concrete and Aggregates 25 (1) (2003).

[7] Turner Fairbank Highway Research Center, Reclaimed concrete materials, available online at: http:// www.tfhrc.gov/hnr20/recycle/waste/rcc2.htm.

[8] Environmental Council of Concrete Organizations, Recycling concrete saves resources eliminates dumping, available online at: http://www.p2pays.org/ref/14 /13602.pdf.

[9] American Society of Testing Material (ASTM), Standard specification for reclaimed concrete aggregate for use as coarse aggregate in Portland cement concrete, available online at: http://www.astm.org.

[10] National Reduction Advisory Committee, Market development study for recycled aggregate products, 2001, available online at: http://www3.gov.ab.ca/env/waste/aow /crd/publications/Recycled_CRD_Aggregates.pdf.

[11] G. Soberon and V. Jose, Relationship between gas adsorption and the shrinkage and creep of recycled aggregate concrete, Cement, Concrete \& Aggregates 25 (2) (2003).

[12] F. T. Olorunsogo and N. Padayachee, Performance of recycled aggregate concrete monitored by durability indexes, Cement and Concrete Research 32 (2) (2002) 179-185.

[13] S. Gómez and M. V. José, Porosity of recycled concrete with substitution of recycled concrete aggregate: An experimental study, Cement and Concrete Research 32 (8) (2002) 1301-1311.

[14] C. S. Poon, Z. H. Shui, L. Lam, H. Fok and S. C. Kou, Influence of moisture states of natural and recycled aggregates on the slump and compressive strength of concrete, Cement and Concrete Research 34 (1) (2004) 31-36.

[15] T. Eighmy and B. Magee, The road to reuse, Journal of Recycled Materials Resource Center 71 (9) (2001) 71-81.

[16] S. Yehia, S. Khan and O. Abudayyeh, Evaluation of mechanical properties of recycled aggregate for structural applications, HBRC Journal 4 (3) (2008).

[17] S. Tabsh and A. Abdelfatah, Influence of recycled aggregate on strength of concrete, Construction and Building Materials 23 (2009) 1163-1167. 